Utah State University

DigitalCommons@USU

3-31-2009

\title{
Aglite Lidar: Calibration and Retrievals of Well Characterized Aerosols from Agricultural Operations Using a Three-Wavelength Elastic Lidar
}

Vladimir V. Zavyalov

Christian C. Marchant

Gail E. Bingham

Thomas D. Wilkerson

Jerry L. Hatfield

Randal S. Martin

See next page for additional authors

Follow this and additional works at: https://digitalcommons.usu.edu/sdl_pubs

\section{Recommended Citation}

Zavyalov, Vladimir V.; Marchant, Christian C.; Bingham, Gail E.; Wilkerson, Thomas D.; Hatfield, Jerry L.; Martin, Randal S.; Silva, Philip J.; Moore, Kori D.; Swasey, Jason; Ahlstrom, Douglas J.; and Jones, Tanner L., "Aglite Lidar: Calibration and Retrievals of Well Characterized Aerosols from Agricultural Operations Using a Three-Wavelength Elastic Lidar" (2009). Space Dynamics Lab Publications. Paper 150.

https://digitalcommons.usu.edu/sdl_pubs/150

This Article is brought to you for free and open access by the Space Dynamics Lab at DigitalCommons@USU. It has been accepted for inclusion in Space Dynamics Lab Publications by an authorized administrator of DigitalCommons@USU. For more information, please contact digitalcommons@usu.edu.

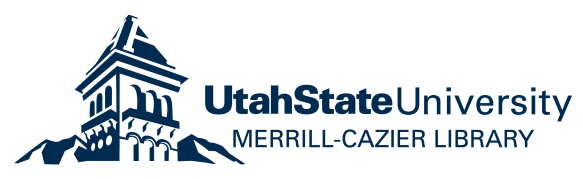


Authors

Vladimir V. Zavyalov, Christian C. Marchant, Gail E. Bingham, Thomas D. Wilkerson, Jerry L. Hatfield, Randal S. Martin, Philip J. Silva, Kori D. Moore, Jason Swasey, Douglas J. Ahlstrom, and Tanner L. Jones 


\title{
Aglite lidar: calibration and retrievals of well characterized aerosols from agricultural operations using a three-wavelength elastic lidar
}

\author{
Vladimir V. Zavyalov ${ }^{1}$, Christian C. Marchant ${ }^{1}$, Gail E. Bingham ${ }^{1}$, \\ Thomas D. Wilkerson ${ }^{1}$, Jerry L. Hatfield ${ }^{2}$, Randal S. Martin ${ }^{3}$, Philip J. \\ Silva $^{3}$, Kori D. Moore ${ }^{1}$, Jason Swasey ${ }^{1}$, Douglas J. Ahlstrom ${ }^{1}$, and Tanner \\ L. Jones ${ }^{1}$ \\ ${ }^{1}$ Space Dynamics Laboratory, 1695 North Research Parkway, North Logan, UT 84341 \\ Tel: 435-797-4116, Fax: 435-797-4599 \\ vladimir.zavyalov@sdl.usu.edu \\ ${ }^{2}$ Agricultural Research Service, National Soil Tilth Laboratory, 2110 University Blvd., Ames, \\ IA 50011-4420, jerry.hatfield@ars.usda.gov \\ ${ }^{3}$ Utah State University, Logan, UT 84322
}

\begin{abstract}
Lidar (LIght Detection And Ranging) provides the means to quantitatively evaluate the spatial and temporal variability of particulate emissions from agricultural activities. AGLITE is a three-wavelength portable scanning lidar system built at the Space Dynamic Laboratory (SDL) to measure the spatial and temporal distribution of particulate concentrations around an agricultural facility. The retrieval algorithm takes advantage of measurements taken simultaneously at three laser wavelengths $(355,532$, and $1064 \mathrm{~nm})$ to extract particulate optical parameters, convert these parameters to volume concentration, and estimate the particulate mass concentration of a particulate plume.

The quantitative evaluation of particulate optical and physical properties from the lidar signal is complicated by the complexity of particle composition, particle size distribution, and environmental conditions such as heterogeneity of the ambient air conditions and atmospheric aerosol loading. Additional independent measurements of particulate physical and chemical properties are needed to unambiguously calibrate and validate the particulate physical properties retrieved from the lidar measurements. The calibration procedure utilizes point measurements of the particle size distribution and mass concentration to characterize the aerosol and calculate the aerosol parameters. Once calibrated, the Aglite system is able to map the spatial distribution and temporal variation of the particulate mass concentrations of aerosol fractions such as TSP, $\mathrm{PM}_{10}, \mathrm{PM}_{2.5}$, and $\mathrm{PM}_{1}$. This ability is of particular importance in the characterization of agricultural operations being evaluated to minimize emissions and improve efficiency, especially for mobile source activities.
\end{abstract}

Keywords: remote sensing, lidar, aerosols, emission rate, agricultural operations

\section{INTRODUCTION}

Agricultural facilities and operations are sources of emissions of gases and particulates in the atmosphere. Quantifying those emissions has proven to be difficult because of the variation among facilities, the spatial arrangement of the emission sources, and the temporal variation in emissions caused by variations in management, biological systems, and weather. Typical designs of monitoring systems for agricultural systems have employed instrumentation designed to evaluate the concentrations of gases or particulates at a specific location around the facility or within the operation. Observations reported by Bingham et al. show the dynamics of air flow and particulate movement around facilities and raise the question of how 
improved methods of measuring particulate and gas emission and movement might aid in our understanding of emissions from agricultural facilities and in the long-term provide a method of comparing systems or management practices [1].

Lidar technology has been successfully applied to qualitatively characterize particulate emissions from agricultural sources [2][3]. The lidar measures the laser light return signal scattered by the atmosphere. This is determined by an integral of the backscatter cross section of the aerosols, with the particle size distribution as a weighting function. As a result, the aerosol backscatter as a function of wavelength is a unique signature of the aerosol size distribution and refractive index of the particles. The physical properties of an aerosol can be retrieved from lidar data using the measured backscatter coefficients and the known relationship between aerosol physical properties and backscatter, as described by Mie scattering theory [4]. Typical lidar systems employed for agricultural applications are based on single wavelength lasers and have limited abilities to quantitatively characterize particulate emission parameters.

Aerosol retrieval techniques for determining physical aerosol parameters (size distribution and concentration) from multi-wavelength lidar have been utilized since the 1980s, and major improvements have been made in the past several years [5][6][7][8][9][10][11]. Unambiguous and stable retrieval of the aerosol physical parameters using only a lidar requires measurements of backscatter coefficients for at least three wavelengths and the aerosol extinction coefficient for at least two wavelengths using additional Raman channels [8][10]; however, there are significant design challenges with building lidars with Raman channels [11].

To date, a significant database of atmospheric aerosol characteristics has been obtained by the combination of satellite and ground based observations [5][12]. These databases can be used to make assumptions on the aerosol properties from each particular source. Using these assumptions, the physical properties of assumed aerosols can be retrieved from measurements of backscatter coefficients of an elastic lidar with three wavelengths [5][13]. In most cases, the accuracy of the retrievals strongly depends on a priori assumptions of the aerosol refractive index and of the type and shape of its size distribution [14].

To quantify emissions from a wide range of variable agricultural sources, a relatively inexpensive, robust, and easily operated lidar system was needed to provide particulate emission measurements in a matter of a few minutes under a wide range of meteorological and operational conditions. Aglite is a three-wavelength elastic lidar system with a $12 \mathrm{~m}$ range resolution and $450 \mu \mathrm{r}$ telescope designed to meet these requirements [15]. The lidar is calibrated using additional aerosol characteristic point measurements to enable the characterization and retrieval of aerosol fractions needed for these evaluations. Converting the lidar returns to aerosol concentration is a complex process requiring significant additional input. This paper presents the approach used in the Aglite lidar calibration and aerosol retrieval process and demonstrates the ability of the lidar system to characterize particulate mass concentration emissions.

\section{METHOD AND INSTRUMENTATION EMPLOYED}

Adequately describing the aerosols encountered at agricultural facilities is a complex process. Particle size distributions are often described using a bimodal log-normal distribution with six independent parameters. In addition, calculating the backscatter properties of an aerosol requires three more variables for complex index of refraction at each wavelength, resulting in as many as nine independent parameters needed to describe an aerosol. Moreover, in most cases the fine and coarse particle modes have different sources and chemical compositions, which can lead to size-dependent complex refractive indices [10]. This may require a total of twelve independent parameters to describe the aerosol, while Aglite has three simultaneous lidar channels available for inversion. 
Furthermore, uncertainties in aerosol chemical composition, non-spherical particle shape, and the variety of environmental conditions combine to make it unfeasible to measure mass concentration purely optically.

In the approach described here, the particulate chemical and physical properties are measured in situ using point sensors that measure the particle size distribution of both particulates emitted at the experiment site and background aerosols. In summary, these point measurements are used to establish the parameters required to invert the lidar equation and retrieve the aerosol concentration as described in section 3. Point measurements are also used to calibrate and validate the results of the lidar retrievals. These measurements are made by MetOne 9722 Optical Particle Counters (OPCs) and AirMetric MiniVol Portable Air Samplers (Filter Particulate Samplers or FPS) aerodynamic particle sampler instruments. (The instruments and manufacturers named herein were used in the research experiments described; however, their use does not constitute an endorsement or preferential treatment by the researchers or the project sponsors.)

The calibration process consists of two major steps. First, the lidar line of site is placed next to the OPC used for calibration to establish a reference calibration point that will be used to convert the lidar return signal to aerosol optical parameters as described in section 3.3. This calibration step is typically performed every $2-5$ min to account for variability of the background aerosols. Secondly, the relationship between aerosol data acquired optically (OPC and lidar) and aerodynamically (FPS) is derived for each experiment setup as a mass calibration parameter. This relationship is described by the mass conversion factor (MCF) [16].

MCF is derived using collocated OPC and clusters of FPS samplers, and the MCF is used to make the conversion from particle volume concentration to mass concentration units (see section 3.2). In the data published here, the MCF was derived from data averaged over one or more days using several collocated OPC and FPS clusters strategically arrayed around the experimental site. The FPS samplers represent a USEPA-approved method of measuring particulate mass concentrations and were used in this study to validate OPC and lidar derived PM concentrations. FPS clusters are located on the upwind side to collect background aerosols and downwind (emission and background aerosols) to provide a truth data set for validation as is discussed in section 6 .

The Aglite lidar system utilized in this work is described in detail by Marchant et al. [15]. It is a single diode-pumped $10 \mathrm{kHz} \mathrm{Nd:YAG} \mathrm{laser} \mathrm{co-aligned} \mathrm{with} \mathrm{a} \mathrm{Newtonian} \mathrm{telescope}$ with a $28-\mathrm{cm}$ diameter primary mirror. The laser operates simultaneously at $1.064 \mu \mathrm{m}$ (IR), $0.532 \mu \mathrm{m}$ (VIS), and $0.355 \mu \mathrm{m}$ (UV) wavelengths with pulse energies of 435,50 , and $93 \mu \mathrm{J}$, respectively. To measure the background and emission aerosol properties, OPCs and FPS are mounted on the array of towers around the facility under study. The OPC sensors have the ability to count and size airborne particles into eight size ranges from 0.3 to greater than 10 $\mu \mathrm{m}$ in diameter with a selectable sample averaging time between 2 and $60 \mathrm{~s}$. Clusters of filterbased portable FPS are collocated with the OPCs. Each sampler in the cluster has a different impaction head that aerodynamically separates the aerosol into the mass fraction of TSP (Total Suspended Particulate), $\mathrm{PM}_{10}, \mathrm{PM}_{2.5}$ or $\mathrm{PM}_{1}$. This allows simultaneous measurement of each mass fraction concentration at the cluster location. The sampling period varies from 4 to 24 hours, based on the estimated background aerosol and emitted concentrations. Each sampler is fitted with a conditioned, pre-weighed Teflon filter and operates at a flow of approximately five liters per minute. Following sampling, the filters are recovered, conditioned, and reweighed for filter catch and determination of each location's mass concentrations.

Meteorological measurements are also made on site to record wind speed and direction, air pressure, temperature, and humidity. Additionally, an Aerodyne Research Inc. Aerosol Mass Spectrometer (AMS) is installed in the auxiliary trailer. This provides high resolution information on the ionic composition and fine particle size distribution of the aerosol. A 
detailed description of the instrumentation and the results of the point measurements are reported by Martin et al. [17].

\section{AEROSOL MASS CONCENTRATION RETRIEVAL}

The process of retrieving aerosol mass concentration from lidar data is illustrated in Fig. 1. The retrieval is outlined as follows. First, the lidar data are preprocessed. The relationships between backscatter, extinction, volume concentration, and mass concentration of the aerosol components are established. Then, the inversion of the lidar equation for backscatter is performed using the form of Klett's [18] solution including background where extinction is proportional to backscatter. Finally, a least-squares method is used to convert backscatter values to aerosol mass concentration using the previously established relationships.

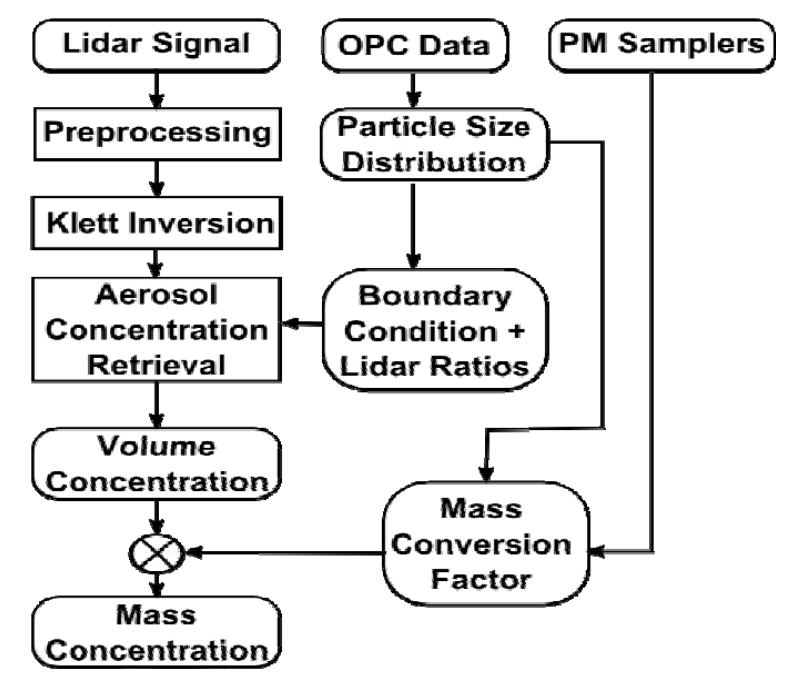

Fig. 1. The Aglite retrieval algorithm flow chart, showing the input locations for the in situ data.

Under this procedure, it is assumed that the aerosol particles are spherical and have a constant index of refraction and density with respect to size. Values of refractive index $\boldsymbol{m}$ for assumed aerosol type are selected from the Handbook of Geophysics and the Space Environment [19] and the OPAC database [20]. As a result, the backscatter and extinction parameters of a particle can be calculated using Mie theory for spherical particles.

Therefore,

$\alpha(\lambda)=\int_{0}^{\infty} \pi r^{2} Q_{\text {ext }}(r, m, \lambda) n(r) d r$
$\beta(\lambda)=\int_{0}^{\infty} \pi r^{2} Q_{\pi}(r, m, \lambda) n(r) d r$

where $r$ is the particle radius, $n(r)$ is the particle size distribution, and Qext and $\mathrm{Q} \pi$ are the extinction and backscatter efficiency functions, which depend on particle radius, wavelength $\lambda$, and complex index of refraction $\mathrm{m}$. It is also assumed that the aerosol is divided into two component scatterers, a homogeneous background component and a varying emission aerosol component. Furthermore, it is assumed that the emission aerosol is well mixed, i.e. only the concentration of the emission aerosol varies with space and time, not the shape of the aerosol size distribution, and that multiple scattering effects can be neglected. The following subsections describe the elements of the flow chart in Fig. 1. 


\subsection{Preprocessing}

The lidar equation can be expressed as:

$$
P(z)=C \cdot G F F(z) \cdot \beta(z) \cdot \exp \left[-2 \int_{0}^{z} \alpha\left(z^{\prime}\right) d z^{\prime}\right]+N,
$$

where $P(z)$ is the measured power at range $z$, and $C$ is the lidar coefficient representing the cumulative effect of lidar output power, receiver area, optics and detector efficiencies. In eq. (2), the wavelength dependence is implicit. The factor $G F F(z)$ is the geometric form factor of the lidar, $\beta(z)$ is the backscatter coefficient at range $z, \alpha(z)$ is the extinction coefficient at range $z$, and $N$ represents the solar background noise component of the signal. Its mean and variance are assumed to be constant.

The mean of $N$ is estimated and subtracted from the data. The shape of the geometric form factor (GFF) is modeled based on the physical parameters of the lidar optics, and the data are normalized by this estimate of the GFF. The difficulty in correctly modeling the GFF is well known. The expected attenuation due the GFF is $80 \%$ at $650 \mathrm{~m}$, so measurements were made at this range or further in order to insure minimal error due to incorrect GFF estimation [15]. Finally, the lidar data are converted to a logarithmic range-corrected form convenient for inversion by Klett's method, expressed as $S(z)$ :

$$
S(z)=\ln \left|\frac{z^{2}(P(z)-N)}{G F F(z)}\right|
$$

\subsection{Point Sensor Data}

Point-sensor instruments are used to determine the relationships between backscatter, extinction, volume concentration, and mass concentration of the aerosol components. The OPC instruments are strategically placed around the research site and measure the particle size distributions of both the background and emission aerosol components. Using (1), backscatter and extinction coefficients for each wavelength are calculated from these data. The relationship between the backscatter coefficients and cumulative volume concentration of the emission aerosol component is established. Additionally, backscatter coefficients from these instruments are used as boundary conditions during the inversion step of the retrieval.

The channel counts of an OPC instrument represent the particle size distribution of the atmospheric aerosols at a single point as a function of time. This in turn gives the backscatter and extinction at that point as a function of time using (1). The cumulative volume concentration as a function of time is also calculated using

$$
V_{k}=\frac{4 \pi}{3} \sum_{i=0}^{2 r i<k} r_{i}^{3} n_{i}
$$

where $\mathrm{n}_{\mathrm{i}}$ is the particle density in size bin $\mathrm{i}$.

In this case, cumulative volume concentration is defined similarly to PM concentration: the fraction of the total volume of particles, whose diameter is less than $\mathrm{k}$ microns, where $\mathrm{k}=$ $1,2.5,10$, or infinity in the case of TSP.

Dividing the extinction coefficients by the backscatter coefficients establishes the ratio of extinction to backscatter, or lidar ratio. Particle normalized values for backscatter $(\tilde{\beta})$ and

cumulative volume concentration $(\widetilde{V})$ are then calculated. This establishes the following relationship between backscatter and volume concentration: 


$$
\left[\begin{array}{c}
\beta_{U V} \\
\beta_{V I S} \\
\beta_{I R}
\end{array}\right]=\left[\begin{array}{c}
\widetilde{\beta}_{U V} \\
\widetilde{\beta}_{V I S} \\
\widetilde{\beta}_{I R}
\end{array}\right] n \text { and }\left[\begin{array}{c}
V_{1} \\
V_{2.5} \\
V_{10} \\
V_{T S P}
\end{array}\right]=\left[\begin{array}{c}
\widetilde{V}_{1} \\
\widetilde{V}_{2.5} \\
\widetilde{V}_{10} \\
\widetilde{V}_{T S P}
\end{array}\right] n,
$$

where $n$ is the particle concentration.

Aerodynamic fractioning FPS samplers are also placed around the research site, colocated with the OPC instruments. These measure the aerosol mass concentration, integrated over a period of time determined by their sample time. A relationship between aerosol mass concentration and aerosol volume concentration, or MCF, is established by dividing the average aerosol mass concentration by the average cumulative volume concentration from the co-located OPCs.

Theoretically, the conversion from particulate cumulative volume concentration to mass concentration is complex, and several simplifying assumptions have to be made, namely that the particles are spherical, have constant density, and have negligible multiple scattering effects. Using co-located OPCs and FPS allows direct calibration of optical instruments (OPC and lidar) by establishing the MCF corresponding to each $\mathrm{PM}_{\mathrm{k}}$ fraction. The calibration parameters are derived from OPC and AirMetric portable $\mathrm{PM}_{\mathrm{k}}$ samplers placed in clusters at the same location. OPC data are averaged over the same period as the sampling time of the co-located FPS, and then $V_{k}$ for each mass fraction is calculated according to (4).

An estimate of the MCF is calculated by dividing the $\mathrm{PM}_{\mathrm{k}}$ mass concentration values from the FPS by the value for $V_{k}$ measured by the co-located OPC. These data are averaged over one or more days in several locations, and a mean value of $\mathrm{MCF}_{\mathrm{k}}$ for the experiment is calculated for each $\mathrm{PM}_{\mathrm{k}}$ fraction:

$$
M C F_{k}=\frac{1}{N} \sum_{i=1}^{N} \frac{P M_{i, k}}{V_{i, k}}
$$

Molecular Rayleigh scattering makes up an important part of the homogeneous background scattering component. A weather station is deployed at the site to record temperature, pressure, and humidity with time, which are then used to model the expected backscatter and extinction contributions due to Rayleigh scattering.

\subsection{Klett Inversion}

Using (4), the lidar equation for two scatterers may be written in the form [18]:

$$
S(z)=\ln |C|+\ln \left|\beta_{B}+\beta_{E}(z)\right|-2 \int_{0}^{z}\left(\alpha_{B}+\alpha_{E}\left(z^{\prime}\right)\right) d z^{\prime}
$$

where the subscript $B$ represents the homogeneous background component, and the subscript $E$ represents the varying emission component.

The standard solution of this equation involves two a priori assumptions. The first assumption is that the relationship between aerosol extinction and backscatter or lidar ratio, here defined as $L=\alpha / \beta$, is known.

The second assumption is that the boundary conditions of (7) must be defined at some reference range. This is done by determining either the extinction coefficients or the backscatter coefficients at the reference range $z_{R}$. 
In this specific case, both assumptions are handled using the OPC point sensor data. The lidar ratios are calculated using the extinction and backscatter values derived from the OPC data as described previously. The value for the boundary condition is obtained by placing the lidar beam next to the calibration OPC at some reference range $z_{R}$ during the lidar measurement. The boundary condition backscatter values for the lidar data are simply the backscatter values derived from the OPCs taken at the same time. The data from a line-of-site OPC calibrate the lidar data. By using coincident OPC data to establish the boundary condition of (7) and determine the relationships of the aerosol properties, the lidar is specifically calibrated for the experiment.

With these constraints satisfied, (7) can be solved formally. Following Klett's standard solution [18], an expression for the emission component backscatter for a single channel is

$$
\beta_{E}(z)=\frac{\exp \left(S^{\prime}(z)-S_{R}^{\prime}\right)}{\beta_{R}^{-1}+2 \int_{z}^{z R} L_{E} \exp \left(S^{\prime}\left(z^{\prime}\right)-S_{R}^{\prime}\right) d z^{\prime}}-\beta_{B},
$$

where the term $S_{R}^{\prime}$ is defined as the value of $S^{\prime}$ at range $z_{R}$ and variables $S^{\prime}$ and $S_{R}^{\prime}$ are defined in terms of the $\mathrm{S}$ function as follows:

$$
S^{\prime}(z)-S_{R}^{\prime}=S-S_{R}-2 L_{B} \int_{z}^{z_{R}} \beta_{B} d z^{\prime}+2 \int_{z}^{z_{R}} L_{E} \beta_{B} d z^{\prime},
$$

where $L_{B}$ and $L_{E}$ represent the lidar ratio for the background and emission components respectively. The sign error in Klett's original equation has been corrected here.

Klett's original solution was derived for atmospheric applications when a lidar is looking straight up, so that the molecular contribution is significant for altitudes above the aerosol boundary layer. For this case, the background lidar ratio $L_{B}$ can be determined from Rayleigh theory and is known to be $8 \pi / 3$. For agricultural applications, all measurements are conducted close to ground level, and the main contribution to atmospheric scattering is due to aerosols. However, for Aglite measurements, molecular Rayleigh scattering can be comparable with Mie background aerosol scattering, especially at shorter (UV) wavelengths.

The extinction and backscatter values from Rayleigh scattering are modeled using measurements of temperature, pressure, and humidity [11][19], and added to the backscatter and extinction values of the background aerosol to form the backscatter and extinction values of the homogenous background component.

\subsection{Aerosol Concentration Retrieval}

Given the recovered backscatter values as a function of range and wavelength from the Klett inversion, they can then be converted to aerosol volume concentration. Expressing the particle normalized backscatter values from (5) and the lidar measured backscatter values (8) in vector form, and applying the Moore-Penrose weighted minimum least-squares solution, results in the value for particle concentration

$$
n(z)=\frac{\widetilde{\boldsymbol{\beta}}_{E}^{T} \mathbf{W} \boldsymbol{\beta}_{E}(z)}{\widetilde{\boldsymbol{\beta}}_{E}^{T} \mathbf{W} \widetilde{\boldsymbol{\beta}}_{E}},
$$

which can be multiplied by the particle normalized cumulative volume concentration vector, resulting in the cumulative volume concentration: 


$$
\mathbf{V}_{E}(z)=\tilde{\mathbf{V}}_{E} n(z)
$$

The term $\mathbf{W}$ is a diagonal weighting matrix, whose diagonal elements are the expected variance of the particle normalized emission backscatter at the corresponding channel.

$\mathbf{W}_{z}=\left[\begin{array}{ccc}\sigma_{U V, z}^{-2} & 0 & 0 \\ 0 & \sigma_{V I S, z}^{-2} & 0 \\ 0 & 0 & \sigma_{I R, z}^{-2}\end{array}\right]$

Having retrieved aerosol volume concentration, all that remains is to multiply it by the $\mathrm{MCF}$, which was calculated previously. At this point, the $k$ th fraction of the aerosol mass concentration of the emission component is known as a function of distance,

$$
P M_{K}(z)=M C F_{K} \cdot V_{K}(z) .
$$

\section{Aerosol Model Sensitivity Analysis}

A sensitivity study was conducted to determine how constraining the particulate size distribution shape affected the stability and accuracy of the retrieval process. Simulations were conducted for monomodal and bimodal log normal distributions with parameters covering the range of particulates encountered during the field experiments. Three types of aerosols were synthesized, and for each type, the backscatter coefficients $\beta_{\mathrm{i}}$ at three wavelengths were calculated using Mie theory (1). Type 1 and type 2 aerosols were constructed for a monomodal distribution typical for fine (subscript $\mathrm{f}$ ) and coarse (subscript c) modes respectively. The following parameters were chosen: $\mathrm{r}_{\mathrm{mf}}=0.15 \mu \mathrm{m}, \mathrm{r}_{\mathrm{mc}}=2.0 \mu \mathrm{m}$, $\sigma_{\mathrm{f}}=\sigma_{\mathrm{c}}=1.5$; and two values for concentration: $\mathrm{N}_{\mathrm{j}}=10^{10}$ and $10^{11} \# / \mathrm{m}^{3}$. For type 3 aerosol, a bimodal distribution was assumed with the mode radius and distribution width of the fine and coarse modes being the same as for type 1 and type 2 distributions respectively. Two ratios of particle numbers in fine and coarse modes, $\mathrm{N}_{\mathrm{f}} / \mathrm{N}_{\mathrm{c}}=100$ and 1000 , were tested. To account for the diversity of aerosols present in the field, simulations were performed assuming the index of refraction of both water-soluble and dust-like aerosols for each type of distribution.

Simulations were conducted both on noiseless synthetic data and on synthetic data with Gaussian distributed noise added. The backscatter $\beta_{\mathrm{i}}$ noise level values were chosen based on noise levels that are typical over the range of 600 to $1000 \mathrm{~m}$ and for $20 \%$ and full $(100 \%)$ laser power. The signal-to-noise ratio and backscatter coefficient noise of the lidar return is range dependent [15]. At full transmitted power, the ratio of standard deviation to mean value in $\beta_{\mathrm{i}}$ retrievals ranged from 8 to $14 \%$ for IR, from 5 to $12 \%$ for VIS, and from 10 to $18 \%$ for UV wavelengths. At $20 \%$ transmitted power, these errors increase to $15-25 \%$ at IR and VIS wavelengths and to $20-35 \%$ at UV. To cover this range of input noise, two noise ratio values of $\beta_{\mathrm{i}}$ were used: $10 \%$ and $20 \%$.

The statistical analysis of measurement accuracy (absolute error or bias with respect to the true value), measurement uncertainty (root mean square RMS error with respect to the true value), and measurement precision (standard deviation estimated with respect to the mean sample value) were estimated for 50 runs for each aerosol type and condition. Simulations were also conducted with a form of the retrieval algorithm [21] that permitted the retrieval of unconstrained solutions. For the single-mode log normal particle size distribution under the different scenarios of unconstrained parameters of particle size distribution, fixed mode radius ( $\mu$-constrained), and fixed width of the distribution ( $\sigma$-constrained), it was found 
that the unconstrained solution had significantly more error than the fully-constrained solution. Noiseless data produce stable retrievals for all cases with absolute errors in the number concentration not exceeding 4\%. Unconstrained solution on the noisy data can lead to $40-80 \%$ errors in the PM mass concentration estimations. The $\mu$-constrained errors of particulate mass fraction for $\mathrm{PM}_{2.5}$ and $\mathrm{PM}_{10}$ retrievals can be reduced to $10-14 \%$ at full laser power and to $15-20 \%$ at $20 \%$ power.

The bimodal particle size distribution simulation results are summarized in Table 1. The errors are presented as a ratio of the standard deviation of the cumulative volume concentration $\mathrm{V}_{\mathrm{k}}$ to its mean value in percent. In this case, the solution of the unconstrained bimodal distribution tends to converge to a single mode distribution with mode radius between the fine and coarse mode radii resulting in large errors in PM concentration (higher than $150 \%$ ). Better results are achieved when distribution width is fixed for both modes. However, while the errors are not as large for smaller PM fractions (20-40\%), they reach $130 \%$ for TSP mass concentration. The best results are when constraints are applied to both the mode radius and the distribution width for both fine and coarse modes.

Table 1. Cumulative volume concentration error for the bimodal particle size distribution estimated with different constraints derived from in situ data with $10 \%$ and $20 \%$ uncertainty in the backscatter coefficients. Errors are expressed as a ratio of $\sigma$ over the mean cumulative volume concentration (\%).

\begin{tabular}{|c||c|c||c|c||c|c||c|c|}
\hline \multicolumn{1}{|c||}{ CVC } & \multicolumn{2}{c||}{$\mathrm{V}_{1}$} & \multicolumn{2}{c||}{$\mathrm{V}_{2.5}$} & \multicolumn{2}{c||}{$\mathrm{V}_{10}$} & \multicolumn{2}{c|}{$\mathrm{V}_{\text {TSP }}$} \\
\hline \hline$\Delta \beta$ & $10 \%$ & $20 \%$ & $10 \%$ & $20 \%$ & $10 \%$ & $20 \%$ & $10 \%$ & $20 \%$ \\
\hline$\mu$-constr & $19 \%$ & $37 \%$ & $10.5 \%$ & $19 \%$ & $12 \%$ & $30 \%$ & $125 \%$ & $180 \%$ \\
\hline$\sigma$-constr & $32 \%$ & $41 \%$ & $27 \%$ & $36 \%$ & $45 \%$ & $58 \%$ & $87 \%$ & $130 \%$ \\
\hline$\mu, \sigma$-constr & $11 \%$ & $22 \%$ & $10 \%$ & $20 \%$ & $12 \%$ & $25 \%$ & $18 \%$ & $35 \%$ \\
\hline
\end{tabular}

The bimodal particle size distributions retrieved from 50 runs are compared for the $\mu$-constrained and $\mu, \sigma$-constrained solutions in Fig. 2a and Fig. 2b, respectively. For $\mu$, $\sigma$ - constrained solutions, errors in $\mathrm{PM}_{1}, \mathrm{PM}_{2.5}$, and $\mathrm{PM}_{10}$ mass concentration are $<12 \%$ ( $20 \%$ in TSP) for $10 \%$ input errors (full laser power). The retrieval errors at $20 \%$ laser power are $<25 \%$ for $\mathrm{PM}_{1}, \mathrm{PM}_{2.5}$, and $\mathrm{PM}_{10}$ mass concentrations, but increase to $35 \%$ for TSP.

The results of this simulation clearly show that an acceptable level of error in retrievals of bimodal particle size distributions can be achieved only by constraining both the mode radius and width of both fine and coarse modes. This implies that for high levels of noise, an acceptable level of error in particle concentration retrieval can be achieved only if the shape of the particle size distribution is already fully characterized. For this reason, the retrieval algorithm described in Section 3 uses a priori knowledge of the aerosol distribution shape from OPC sensors.
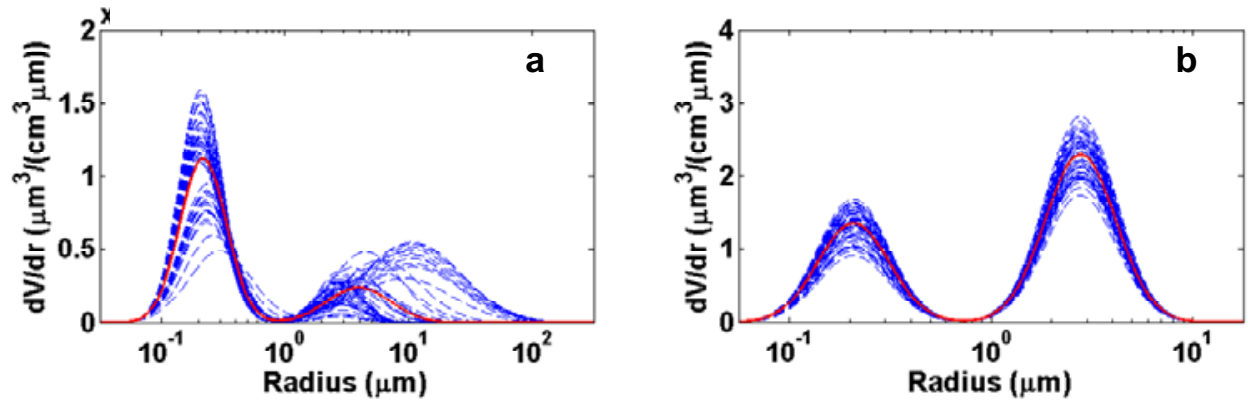

Fig. 2. Spread of the retrieved results of 50 runs for bimodal particle size distribution with $\mu$-constrained (a) and $\mu, \sigma$-constrained (b) solutions with $10 \%$ error in $\beta$. 


\section{RETRIEVAL ERROR ESTIMATION}

In this section, the measured data from field measurements are used to develop an estimate of the lidar particulate mass measurement error. Optical (lidar and OPC) particulate cumulative volume concentration error has been estimated comparing the OPCs with each other and with EPA standard instrumentation. The mass concentrations derived from optical measurements are not measured directly but calculated from several physical parameters, each of which has a mean value and an error. The resulting error can be estimated by a standard error propagation method. For a function $f$ derived from several measured variables $x_{i}$ with independent measurement precision $\Delta x_{i}$ the uncertainty of $\Delta f$ can be approximated by [22]:

$$
\Delta f^{2}=\sum_{i=1}^{n}\left(\frac{\partial f}{\partial x_{i}} \Delta x_{i}\right)^{2} \text {. }
$$

Using this approach, an expression for measurement uncertainty of lidar mass concentration retrievals can be derived from (11) and (13). Assuming independent errors in particulate mass concentration measured by FPS and cumulative volume concentration measured by OPC and lidar instruments, the relationship is

$$
\left(\frac{\Delta P M_{L}}{P M_{L}}\right)^{2}=\left(\frac{\Delta M C F}{M C F}\right)^{2}+\left(\frac{\Delta V_{L}}{V_{L}}\right)^{2},
$$

where the uncertainty in the MCF can be estimated from (6) as

$$
\left(\frac{\Delta M C F}{M C F}\right)^{2}=\left(\frac{\Delta P M_{S M}}{P M_{S M}}\right)^{2}+\left(\frac{\Delta V_{O P C}}{V_{O P C}}\right)^{2} .
$$

The parameters $\Delta \mathrm{PM}_{\mathrm{SM}}$ and $\Delta \mathrm{PM}_{\mathrm{L}}$ represent uncertainty in $\mathrm{PM}$ concentration measured by FPS and lidar respectively, while $\Delta \mathrm{V}_{\mathrm{OPC}}$ and $\Delta \mathrm{V}_{\mathrm{L}}$ are errors in cumulative volume concentration calculated from OPC and lidar data respectively.

It is possible to estimate the measurement errors of the parameters in (15) and (16). Chow et al. [23] have shown that errors of mass concentrations measured by FPS do not exceed $8 \%$. The precision of the OPC sensors was measured by taking measurements for a period of time with all of the OPCs collocated. The estimated precision error during this experiment did not exceed $10 \%$ for $\mathrm{PM}_{2.5}$ and $\mathrm{PM}_{10}$ fractions and is about $15 \%$ for $\mathrm{PM}_{1}$ and TSP mass fractions. These results agree well with independent estimations by Binning et al. [16] for a custom-built OPC system. Total errors in MCF calculations were then estimated using (16). These errors do not exceed $12 \%$ for $\mathrm{PM}_{2.5}$ and $\mathrm{PM}_{10}$ fractions and are about 15$18 \%$ for $\mathrm{PM}_{1}$ and TSP fractions. It is important to note that since the estimated uncertainty of cumulative volume concentration represents precision, the MCF can be biased, and the uncertainty in the MCF also represents precision, not accuracy.

During Aglite field experiments, the MCF was estimated for each campaign. The data were collected in several locations over a period of several days, and the mean values of MCF and its precision were estimated for each PM fraction, for background and emissions separately. These values are summarized in Table 2, which shows that the precision of the MCF varies in the range of $10-20 \%$, depending on the experimental conditions. In general, these data agree well with the error estimations presented previously. Higher values of MCF errors are mostly due to influence of fugitive dust on the FPS (swine facility and almond orchard) or variable wind direction (cotton gin) during the FPS collection period. 
Table 2. Comparison of aerosol type and MCF from three campaigns. Measurement precision of mean MCF is presented in terms of the $95 \%$ confidence interval.

\begin{tabular}{|c|c|c|c|c|}
\hline & & Swine Facility & Almond Orchard & Cotton Gin \\
\hline \multirow{4}{*}{$\begin{array}{c}\text { Background } \\
\text { aerosol }\end{array}$} & Aerosol type & $\begin{array}{l}\text { Continental } \\
\text { clean }\end{array}$ & $\begin{array}{c}\text { Continental } \\
\text { polluted }\end{array}$ & $\begin{array}{l}\text { Continental } \\
\text { clean }\end{array}$ \\
\hline & $\mathrm{PM}_{2.5}$ & $4.7 \pm 0.7$ & $6.6 \pm 2.8$ & $1.6 \pm 0.6$ \\
\hline & $\mathrm{PM}_{10}$ & $1.9 \pm 0.2$ & $2.2 \pm 0.6$ & $0.9 \pm 0.5$ \\
\hline & TSP & & $2.2 \pm 0.8$ & \\
\hline \multirow{4}{*}{ Emissions } & Aerosol type & Water-soluble & Mineral & Mineral+Organic \\
\hline & $\mathrm{PM}_{2.5}$ & $4.2 \pm 0.75$ & $6.3 \pm 2.2$ & $1.25 \pm 0.22$ \\
\hline & $\mathrm{PM}_{10}$ & $2.5 \pm 0.4$ & $1.8 \pm 0.4$ & $0.73 \pm 0.18$ \\
\hline & TSP & & $1.4 \pm 0.5$ & $0.65 \pm 0.3$ \\
\hline
\end{tabular}

Errors in the cumulative volume concentration retrieved from the lidar data were estimated by measuring the standard deviation of a 2-4 minute stationary stare through a homogeneous atmosphere. These estimations were conducted during all three field campaigns, and they agree well with the simulation results presented in Table 1. Using (16), total errors in mass concentration retrieved from the lidar data were estimated. The results are presented in Table 3 for $10 \%$ and $20 \%$ MCF errors.

Table 3. Lidar mass concentration error in percent estimated for different particulate mass fractions and assumed error in MCF.

\begin{tabular}{|c|c||c|c||c|c||c|c||c|c|}
\hline \multicolumn{2}{|c||}{ Size fraction } & \multicolumn{2}{c||}{$\mathrm{PM}_{1}$} & \multicolumn{2}{c||}{$\mathrm{PM}_{2.5}$} & \multicolumn{2}{c|}{$\mathrm{PM}_{10}$} & \multicolumn{2}{c|}{ TSP } \\
\hline \hline \multicolumn{2}{|c|}{ Laser power } & $100 \%$ & $20 \%$ & $100 \%$ & $20 \%$ & $100 \%$ & $20 \%$ & $100 \%$ & $20 \%$ \\
\hline \multirow{2}{*}{$\begin{array}{l}\text { MCF } \\
\text { error }\end{array}$} & $10 \%$ & $15 \%$ & $24 \%$ & $14 \%$ & $22 \%$ & $16 \%$ & $27 \%$ & $20 \%$ & $36 \%$ \\
\cline { 2 - 10 } & $20 \%$ & $23 \%$ & $30 \%$ & $22 \%$ & $28 \%$ & $23 \%$ & $32 \%$ & $27 \%$ & $40 \%$ \\
\hline
\end{tabular}

Summarizing these results, the measurement precision of PM mass concentration retrieved from lidar data can be estimated as $14-27 \%$ for the lidar system operating at full laser power and $22-40 \%$ for lidar operating at $20 \%$ power. The precision of lidar measurements strongly depends on the precision of the MCF, which in turn depends on the homogeneity of atmospheric conditions during field experiments and the mixing of background and emission aerosols in the FPS during their sampling period. Because of the relative insensitivity of optical instruments (OPCs and lidar) to larger particles, the errors in MCF measurements and lidar retrievals for TSP mass concentrations are larger. This is demonstrated by experimental data (see Table 3 ).

\section{EXPERIMENTAL RESULTS}

Several field measurement campaigns have been conducted with the Aglite system, including experiments at a swine feeding facility in Iowa and an almond orchard and cotton gin in California. Data presented in the following sections have been selected to demonstrate system performance and error analysis and are not intended as an emission analysis. 


\subsection{Site descriptions}

A schematic diagram of the Aglite system setup at the deep-pit swine production facility near Ames, Iowa is shown in Fig. 3 (this setup is representative of most experimental sites). The Iowa experiment was conducted from August 24 to September 8, 2005. The facility consisted of three separate parallel barns, each housing approximately 1,250 pigs. The area around the facility was topographically flat and surrounded by soybean and cornfields. An unpaved road bordered the swine production facility to the south, and fugitive dust events from the road were captured during lidar observations.

Particulate emissions from barns were localized at a distance of $\sim 650 \mathrm{~m}$ from the lidar, while fugitive dust clouds appeared at a variety of ranges. A number of OPC instruments and FPS were placed around the facility to provide background and plume data for lidar calibration. FPS were not grouped in clusters for this experiment, but instead were spread around the facility to provide better coverage. $\mathrm{PM}_{10}$ and $\mathrm{PM}_{2.5}$ mass fractions were not collected simultaneously, as the sample heads were changed halfway through the experiment. $\mathrm{PM}_{2.5}$ was sampled from August 24 through September 1, and $\mathrm{PM}_{10}$ from September 2 through September 9. The particle size volume distributions of the three components (background, emission, fugitive dust) are shown in Fig. 4a.

$t_{1}$

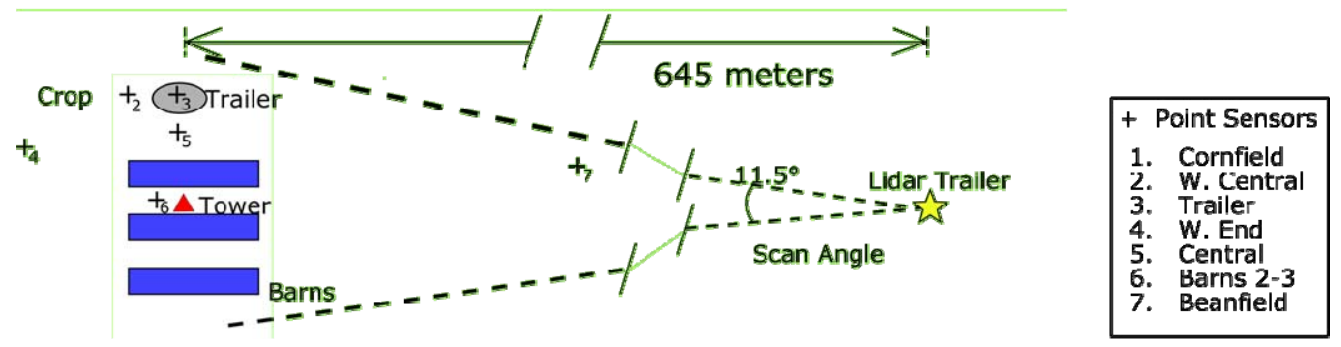

100 meters

Dirt Road

Fig. 3. A typical experimental site layout showing locations of in-situ sensors and the Lidar (distance from lidar to the barns is $\sim 650 \mathrm{~m}$ and is out of layout scale).

The almond orchard experiment was conducted at the Nickels Soils Laboratory research farm near Dunnigan, California from September 26 to October 11, 2006. Harvesting included tree shaking, sweeping, and pickup operations that produced dust plumes from the tree canopy and bare surface soil localized at the point of harvesting. Typical arrays of pointsensor instruments were installed on both the down- and up-wind sides of the orchard. Due to the significant amount of dust emission during harvesting and the short time requirements of the operations, the sampling times of the FPS were reduced to between 2 and $4 \mathrm{hrs}$.

The winds during some of the experiment periods were light and variable, and the orchard under study was surrounded by other almond orchards that were also intensively harvested during the study period. On these days the experimental conditions challenged the entire Aglite system's ability to separate background and in-plume aerosols parameters because: 1) the variable wind did not allow unambiguous up-wind and down-wind conditions, and 2) adjacent neighbor harvesting violated the assumption of a homogeneous background atmosphere component. This can be seen in Fig. 4b, where it is clear that the emission component is not fully separated from the background component. These issues were 
mitigated by waiting for favorable conditions, but showed the system was not as immune to the effects of local environmental conditions as was originally hoped.

The cotton gin experiment was conducted in California's southern San Joaquin Valley from December 10 to 15,2006 . Cotton is subjected to three basic conditioning processes (drying, cleaning and extracting) before it is processed to separate lint and seed. An air handling system, which moves cotton from the trailer through the processes to the bale, is potentially a large source of particulate matter emission. All conveying air was cleaned by a cyclone before being released to the atmosphere. During this experiment the predominant wind direction changed diurnally between morning and evening hours. A downwind tower with the normal cluster of point sensors was located $\sim 150$ m northwest of the gin, while an upwind tower was located $\sim 450 \mathrm{~m}$ south with the same instrument array. Separating upwind and downwind PM data was critical though difficult. Fig. 4c illustrates the OPC-measured background component distribution, while the emission component is illustrated in Fig. $4 \mathrm{~d}$.

\subsection{Field site aerosol models}

Data measured in situ are used to define the aerosol particle size distribution for each experiment. Examples of measured particle size distributions for the summer time Iowa atmosphere (Fig. 4a) and the fall California almond harvest (Fig. 4b) show bimodal distributions with different ratios of number concentration in fine and coarse modes. Fugitive dust in Iowa and emissions from the cotton gin processing and almond orchard harvesting were mostly composed from mineral aerosols exhibiting the properties of large particles [12].
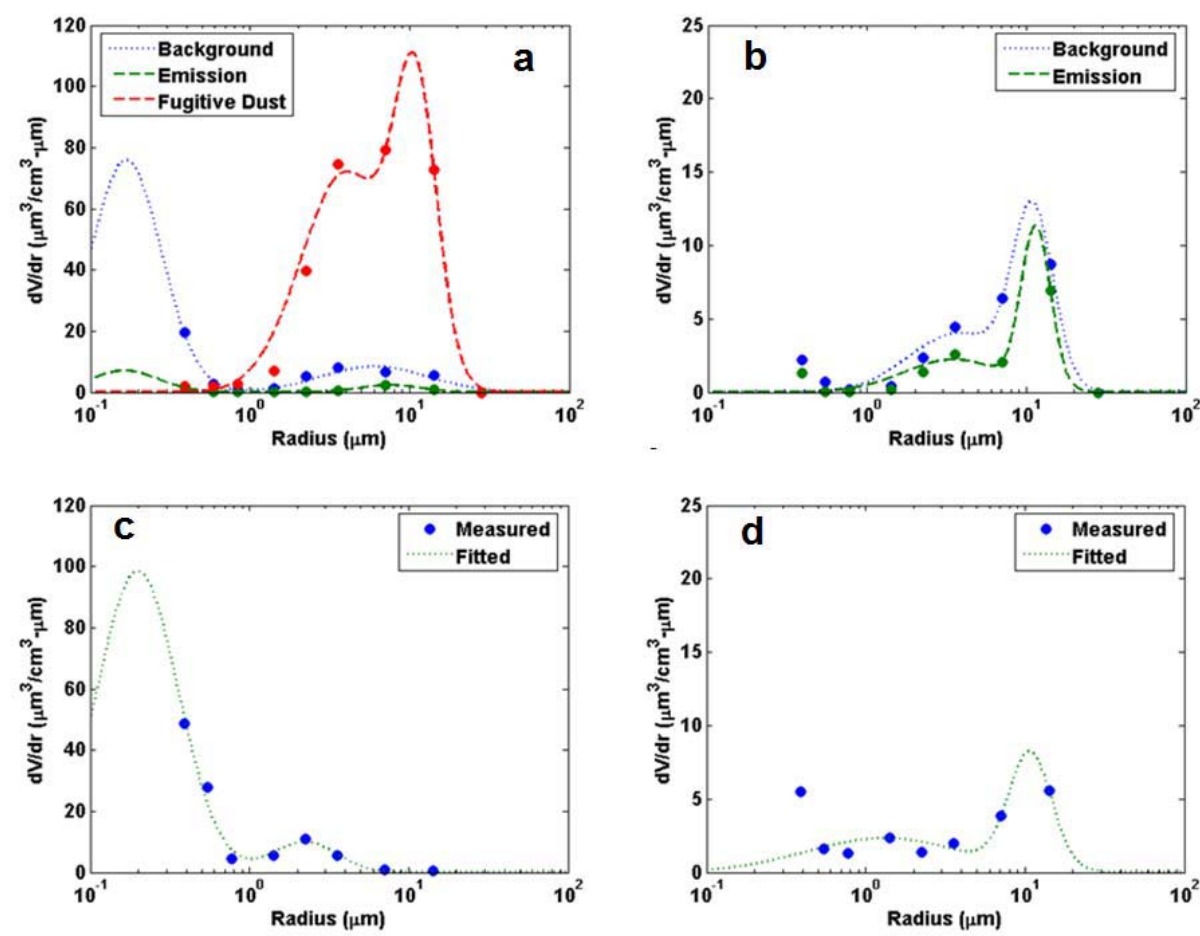

Fig. 4. (a) Size distribution comparison of background and emission aerosol components measured by OPC around swine faculty. (b) Almond harvest background and emission component comparison. (c) Comparison of a bimodal log normal fit to OPC measured background component distribution from cotton gin operation. (d) Comparison of bimodal log normal fit to OPC measured emission component. 
The background aerosols for all three campaigns were consistent with the continental well mixed atmospheric model [19]. Bimodal log normal distribution fits of the distributions are also shown in Fig. 4. The approximation is made using a minimum-least squares fit of a bimodal log normal distribution (dotted or dashed line) to the particle volume distribution calculated using OPC data (heavy dots).

\subsection{Mass concentration retrievals}

\subsubsection{Swine production facility}

The particulate loading measured by the FPS for an eight-day period at different locations around the swine farm was analyzed by Martin et al. [17] and is summarized in Fig. 5a. The error bars show $95 \%$ confidence intervals for the series of filters collected at each location during the period. Fig. 5 b shows a 23 -hour time series collected by an OPC located at the "Central" location in Fig. 3. The OPC number counts for each $20 \mathrm{~s}$ period were converted to $\mathrm{PM}_{10}$ concentration using (13). Large spikes represent fugitive (road) dust events, while the base signal shows the variability of the total aerosol loading (background and emissions).

A direct comparison of OPC and lidar measurements taken with the lidar staring past the OPC is shown in Fig. 6a. These data were taken on September 5, 2005. The comparison of the $20 \mathrm{~s}$ OPC sample and the $1 \mathrm{~s}$ averaged, $12 \mathrm{~m}$ range bin lidar data is in good agreement for both the fugitive dust and baseline data. Whatever differences were observed could be related to the fact that the OPC measures at a single point, while the lidar yields results for a larger volume. In these figures OPC data have been converted to PM using the MCF from Table 2. A simultaneous comparison of $\mathrm{PM}_{10}$ mass concentration at two locations is shown in Fig. $6 \mathrm{~b}$, which represents the first $100 \mathrm{~s}$ of data in Fig. 6a. The co-located lidar and OPC plume measurements were taken at the central tower, 12.6 meters above the ground, while the colocated background measurements were taken at an up-wind location. In many cases the particulate emissions from the swine facility only slightly exceeded the background aerosol loading. Lidar returns were still sensitive enough that these small variations are easily seen due to their spatial localization in the return lidar signal.

a

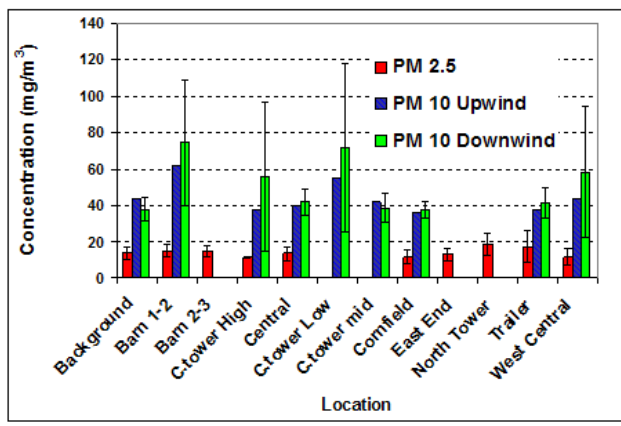

b

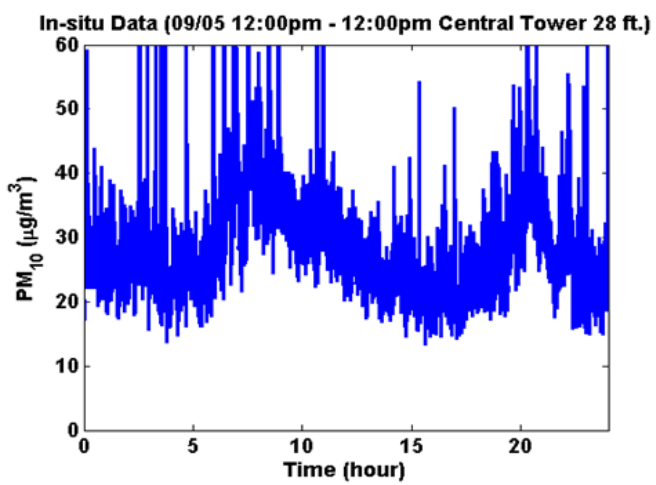

Fig. 5. (a) Particulate mass concentration measured with filter particulate samplers (FPS) at different locations around an Iowa swine finishing facility. b) Particle mass concentration PM10 derived from 24 hours of OPC sensor data (09/05/06-09/06/06).

In addition to the direct comparison between OPC and lidar measurements, a comparison between lidar and FPS data was also made. Several FPS measurements were taken for a 23hour period from September 4 to 5 for both in-plume and background locations. These are listed in Table 4, along with the standard deviation of the measurements. The average and standard deviation of PM concentration were also calculated from OPC data over the same 
time period. Three 20-minute lidar tower stare time series were taken at different times of day on September 5th and averaged to provide a one-hour ensemble average.
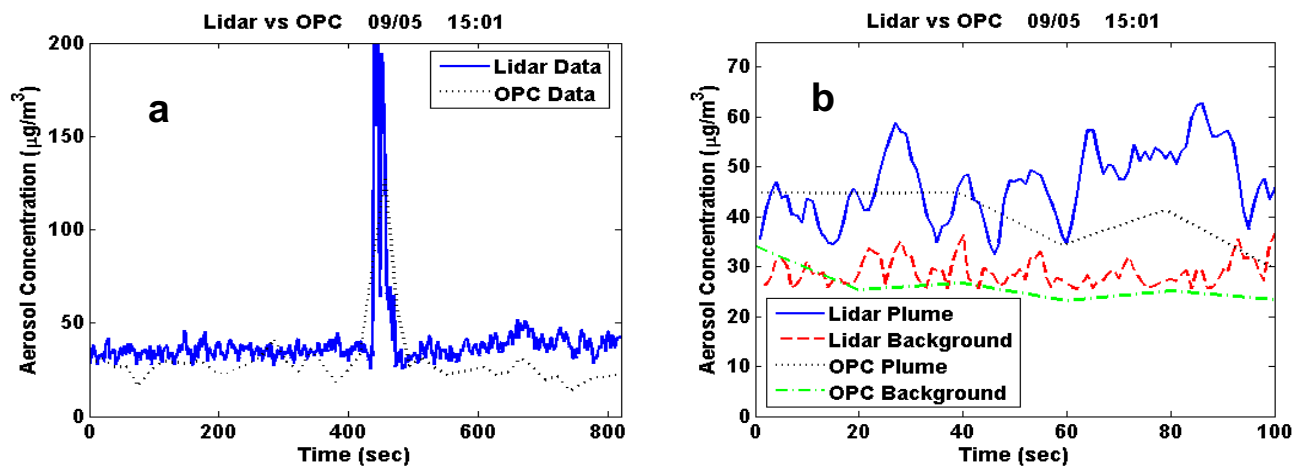

Fig. 6. Time series of $\mathrm{PM}_{10}$ mass concentration measurements from collocated OPC and Lidar: a) $\mathrm{PM}_{10}$ time series with the lidar looking past middle central tower OPC. b) Middle central tower (plume) compared with the upwind tower (background).

Average PM concentration was calculated both for the case where fugitive dust events were found in the data, and for the case where they were selectively removed. The variances of PM concentration for the OPC instruments and lidar include both measurement errors and the natural variability of aerosol loading during sampling time. Within the range of this variability, OPC and lidar retrieved mass concentrations are in excellent agreement with average mass concentrations measured by FPS for both background and total aerosol loading. The comparison of FPS, OPC instruments, and lidar measurements is made in Table 4 for background and in-plume locations.

Table 4. Particle mass concentration measured with FPS, OPC, and lidar from in-plume (Central tower) and background (beanfield) locations at the Iowa swine facility. Collocated 1-hr lidar stare data are compared with 23-hr OPC data.

\begin{tabular}{|c||c|c||c|c||c|c|}
\hline \multicolumn{1}{|c||}{} & \multicolumn{2}{c||}{$\begin{array}{c}\text { FPS } \\
\text { (23 hour base })\end{array}$} & \multicolumn{2}{c||}{$\begin{array}{c}\text { OPC data } \\
\text { (23 hour base })\end{array}$} & \multicolumn{2}{c|}{$\begin{array}{c}\text { Lidar data } \\
\text { (1 hour base })\end{array}$} \\
\cline { 2 - 8 } & Background & Plume & Background & Plume & Background & Plume \\
\hline \hline PM $_{10}$ with dust & $38.7 \pm 5.4$ & $49.4 \pm 8.3$ & $34.4 \pm 24$ & $42.2 \pm 28$ & $37.1 \pm 18$ & $52.8 \pm 21$ \\
Without dust, $\mu \mathrm{g} / \mathrm{m}^{3}$ & & & $28.6 \pm 7.8$ & $38.7 \pm 7.8$ & $30.2 \pm 2.5$ & $46.4 \pm 6.5$ \\
\hline \hline $\mathrm{PM}_{2.5}$ with dust & $13.3 \pm 3.2$ & $14.7 \pm 3.3$ & $14,3 \pm 9.0$ & $17.2 \pm 9.7$ & $11.2 \pm 7.2$ & $12.8 \pm 6.5$ \\
Without dust, $\mu \mathrm{g} / \mathrm{m}^{3}$ & & & $13.7 \pm 4.7$ & $16.7 \pm 6.6$ & $9.5 \pm 0.8$ & $11.6 \pm 1.4$ \\
\hline
\end{tabular}

\subsubsection{Almond orchard and cotton gin}

In both the almond orchard and cotton gin campaigns, particulate emission concentrations were significantly higher than the background aerosol. Both campaigns added new challenges that required expansion of the existing technique and provided lessons for future measurement series.

The data presented for swine facility were all collected with the lidar staring in a constant direction for some time adjacent to the OPCs and FPS. A significant value of the lidar is illustrated in Fig. 7, where two scans over a cotton gin are shown. Fig. 7A shows the gin in 
normal operation with the cyclone and seed pile plumes clearly identified. Fig. 7B shows a scan of the same area, but it was collected during a cycle trash collection event. Here, the emission from the intermittent operation overwhelms the steady state process. Like the road dust plumes observed at the swine farm, being able to identify and quantify these emission sources are critical to efficient process management.
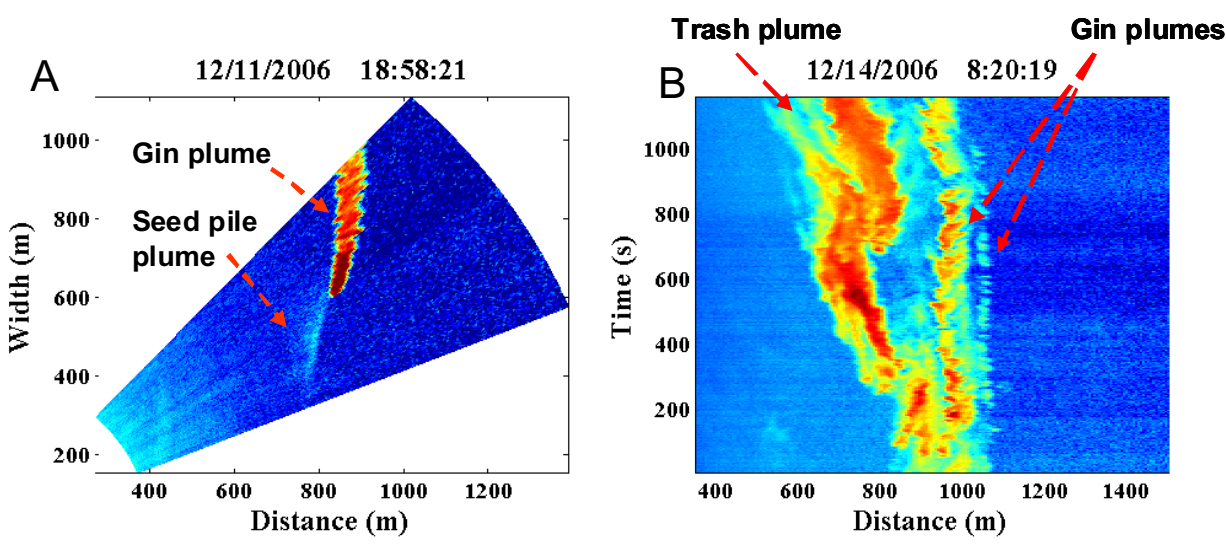

Fig. 7. Horizontal 2D slices of $\mathrm{PM}_{10}$ particulate mass concentration distributions measured during normal (A) and disturbance (B) occurrences at a cotton gin facility. The cyclone trash handling process provides a more intense, but shorter term emission source.

Intermittent processes during the cotton gin campaign and the moving local emission source (harvesting machinery) at the almond orchard meant that these sources were temporally and spatially variable. An example of the problem that arises when comparing open air measurements of a mobile plume between a point sensor like the OPC and the lidar is illustrated by Fig. 8 .

Two towers were erected around the cotton gin facility, one northwest of the facility and one southeast. At the time when the data in Fig. 8 were collected, the northwest tower was downwind of the facility. $\mathrm{PM}_{2.5}$ time series data were derived from an OPC mounted on the downwind tower. The OPC samples the atmosphere using a single $1-\mathrm{cm}$ diameter inlet with an intake rate of .331 every $20 \mathrm{~s}$. The lidar data are taken from the closest measurement range bin, which represents a cylinder $\sim 12 \mathrm{~m}$ long (wavelength dependent) and about $1 \mathrm{~m}$ in diameter with a sampling period of $1 \mathrm{~s}$, meaning the lidar is sampling almost 50001 of air every second. As a result, the lidar measurements have much higher temporal variation $(\sim 10$ times) in the PM concentration measured at that point than the measurements of the collocated in situ OPC.

Fig. 8 shows a time series comparison between the lidar and OPC. Much of the difference between the plots can be explained by the large difference in sampling volume between the two instruments, or edge-of-the-plume effects, while the overall variability of the data is due to the variable wind direction during the period, which caused the plume to move on and off the point sensor. While the point sensor misses sampling the plume for small wind direction changes, the plume just moves to other sample locations in the lidar beam.

The results of particulate mass measurements with tower based clusters of in situ instruments (FPS and OPCs) and lidar ensemble averages are presented in Table 5. The OPC data were averaged over the sampling time of FPS, while the lidar data were averaged for only $0.5 \mathrm{hrs}$. The errors for the OPCs and lidar are presented as the standard deviation measured over the averaging time. In this case PM concentrations are compared only within a single measurement cluster of FPS, so the standard deviation for the FPS cannot be calculated. The lidar data have a much higher sample rate and are averaged over a shorter 
time and show large variability within this time frame, which is clearly illustrated in Fig. 8. Nevertheless, in general the OPC and lidar averaged data are in a good agreement with colocated FPS measurements for both the almond orchard and cotton gin campaigns.

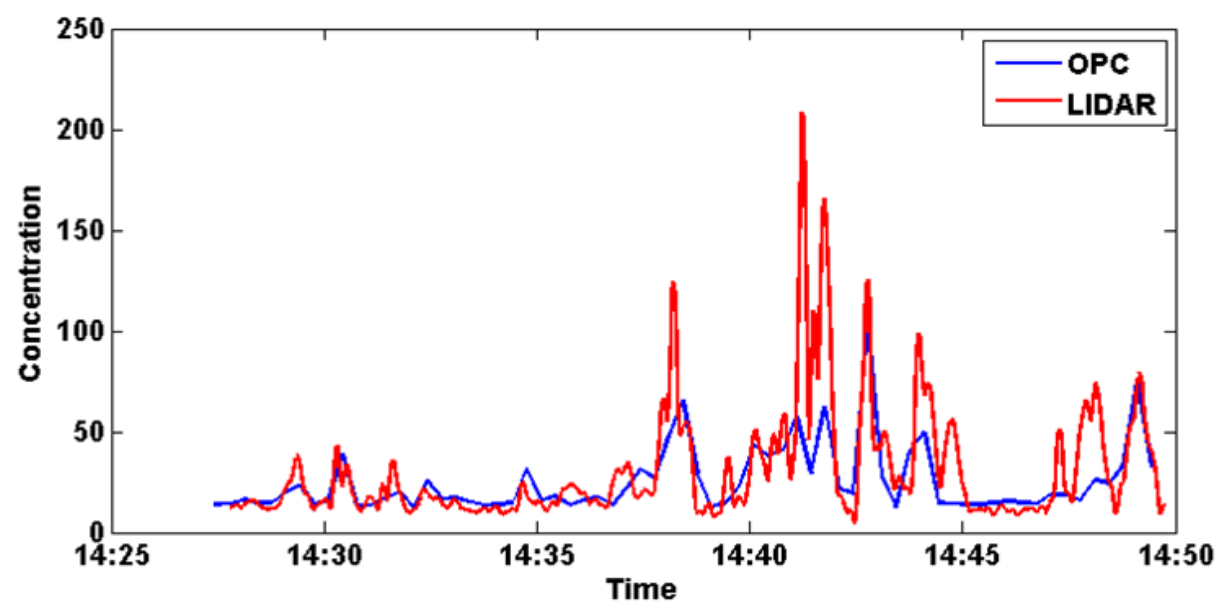

Fig. 8. Optically derived $\mathrm{PM}_{2.5}$ mass concentration $\left(\mu \mathrm{g} / \mathrm{m}^{3}\right)$ measured at the downwind tower. Peaks correspond to times when the plume impacted the OPC measurement volume and the adjacent lidar range bin.

Table 5. Particle mass concentration measured with FPS, OPC, and lidar at the almond orchard and the cotton gin. Collocated lidar stare measurements are averaged for $0.5 \mathrm{hrs}$ while samplers and OPC data are averaged for $4-8 \mathrm{hrs}$.

\begin{tabular}{|c|c|c|c|c|c|}
\hline \multicolumn{2}{|c|}{ PM fraction } & $\mathrm{PM}_{1}$ & $\mathrm{PM}_{2.5}$ & $\mathrm{PM}_{10}$ & TSP \\
\hline \multirow{3}{*}{$\begin{array}{c}\text { Almond } \\
\text { Orchard } \\
10 / 10 / 06\end{array}$} & Airmetric, $4 \mathrm{hr}$ & - & 22.9 & 58.6 & 116 \\
\cline { 2 - 6 } & OPC, $4 \mathrm{hrs}$ & $2.8 \pm 1^{*}$ & $20.1 \pm 28.1$ & $71.2 \pm 110$ & $136 \pm 170$ \\
\cline { 2 - 6 } & Lidar, 0.5 hrs & $2.4 \pm 4.1^{*}$ & $25.8 \pm 68$ & $42.0 \pm 110$ & $87.2 \pm 224$ \\
\hline \hline \multirow{2}{*}{$\begin{array}{c}\text { Cotton } \\
\text { Gin } \\
12 / 12 / 06\end{array}$} & Airmetric, $8 \mathrm{hrs}$ & 23.2 & 27.4 & 35.6 & 59.6 \\
\cline { 2 - 6 } & OPC, $8 \mathrm{hrs}$ & $21 \pm 3.5$ & $30.7 \pm 5.1$ & $49.1 \pm 22$ & $83.2 \pm 101$ \\
\cline { 2 - 6 } & Lidar, $0.5 \mathrm{hrs}$ & $27.3 \pm 5.4$ & $33.6 \pm 6.7$ & $49 \pm 9.7$ & $76.2 \pm 15.2$ \\
\hline \hline
\end{tabular}

* $\mathrm{PM}_{1}$ concentration was estimated using the same MCF estimation for $\mathrm{PM}_{2.5}$ fraction.

\section{DISCUSSION}

We have compared our error analysis with measurements of the observed local variability of collocated measurements with OPS and FPS of various field measurements. The lidar data in Table 4 and Table 5 were measured at $20 \%$ laser power. The standard deviation of lidar PM mass concentration estimated for the fugitive dust-free signal (see Table 4) varies by $10-15 \%$ of the mean value. These values are lower than the $22-32 \%$ variability measured during the almond and cotton experiments. Our experience has shown that even what appear to be uniform background measurements contain fairly significant spatial structure that contribute to the variability observed in the fast response lidar data. Therefore, the estimates in Table 1 are believed to be conservative for the lidar determined volume particulate concentration error.

The MCF determined in these examples may contribute a fairly large (but undefined here) uncertainty to the lidar determined $\mathrm{PM}_{\mathrm{k}}$. It is seen from Table 2 that in several cases the 
MCFs are similar for background and emitted aerosol components. While the background and emission source aerosol characteristics may be similar in some cases, significant errors in emitted aerosol concentration determination are obvious due to contamination by the background component due to shifting wind direction during long sampling times (4-23 hrs) of the filter-based samplers. At the swine facility, the concentration of emissions often exceeded the background concentration only slightly (by 20-30\%), so that the main filter mass acquired by FPS was largely defined by the background particulate.

At the almond orchard, many of the PM background samplers were influenced by the dust generated from surrounding orchards. Hence, "background" varied significantly from days with no local harvesting and fairly steady winds (continental aerosol) to those with local harvesting (highly variable mineral concentration). At the cotton gin, on the other hand, the background aerosol loading was relatively low and required FPS run times of 8-12 hrs, during which the wind direction changed by $180^{\circ}$. As a result, both sampler locations were exposed to emission aerosol. Based on these results, it was concluded that a fast response mass fraction measurement system is required for agricultural source characterization experiments. To this end, a real time quartz crystal based mass fractionation system has been added to the Aglite system to supplement the FPS in determining MCF.

Despite the challenges of using the FPS, the observed comparisons between the optically derived mass fractions and the FPS-measured mass fractions indicate that this approach shows good agreement between point sensor measurements for data averaged over time. Small differences in the PM concentrations measured with FPS, OPCs, and lidar are mostly due to inherently different measurement techniques. Point measurements cannot reasonably capture the entire local plume. Moreover, the intermittent character of plume emission, variable winds, and local turbulence require the use of statistical or model based approaches. The lidar technique is able to capture the entire plume in space and time and to measure and monitor particulate mass concentrations inside of the plume.

The experimental values of MCF estimated during all three field campaigns were presented in Table 2. A couple of comments should be made with respect to these data. First, there is strong dependence of MCF on the $\mathrm{PM}_{\mathrm{k}}$ fraction that cannot be explained by the dependence of particle density on its size. Recently Binnig et al. studied the correlation between optical and aerodynamic particle diameters using an OPC and a sharp-cut cyclone [16]. Following their analysis, the MCF in this case can be approximated as follows:

$$
M C F_{k} \approx\left(\frac{d_{S T . k}}{d_{o p t . k}}\right)^{3} \cdot f_{k}^{3} \cdot \rho_{k} \approx\left(\frac{d_{A C . k}}{d_{\text {opt. }}}\right)^{3} \cdot f_{k}^{3} \cdot\left(\frac{\rho_{0}}{\rho_{k}}\right)^{\frac{3}{2}} \cdot \rho_{k}
$$

where $d_{\text {opt }}, d_{\mathrm{ST}}$, and $\mathrm{d}_{\mathrm{AC}}$ represent optical, Stokes, and aerodynamic diameters of the particle, respectively. $\rho_{\mathrm{o}}$ and $\rho$ are the densities of water droplets and particles respectively, and $f$ represents the dynamic shape factor. Binnig et al. [16] found that for many aerosol types there is no constant conversion factor between these diameters because the conversion factor is size dependent. Indeed, converting optical diameter to an aerodynamic one using a simple conversion expression [24] did not improve the size dependence of MCF. The atmospheric aerosols are composed of a mixture of particles of different origins that may have different shape and density in both size modes. This means that for real aerosols, all three parameters in Eq. (17) may be size dependent, leading to a strong dependency of MCF on the PM fraction. Second, some of the difference in MCF values estimated during different campaigns can be explained by the different origins of emission and background particulate mixtures. For instance, the smaller MCF values estimated for the cotton gin reflect the significant contribution from relatively long organic fibers in total aerosol loading.

Under the calibration approach presented in this study, the $\mathrm{MCF}_{\mathrm{k}}$ for each $\mathrm{PM}_{\mathrm{k}}$ fraction takes care of most of the experimental uncertainties in the aerosol density, irregularity of the 
particle shape, and the relationship between particle optical and aerodynamic properties. The lidar mass concentration data in this approach are highly correlated to the FPS data and provide a surrogate for the long term averaged filter-based mass measurements. The averaging procedure over many correlated measurements statistically improves the accuracy of MCF estimation and discards outliers in OPC and FPS measurements.

It should be noted that filter-based FPS represent mass concentration of dry particles, while optical instruments like OPCs and lidar are sensitive to the particle physical properties affected by ambient air humidity [25]. The lidar mass fraction data reported in this paper are tuned to the sampler data and thus represent the mass concentration of dry aerosol particles.

\section{CONCLUSION}

SDL has developed a three-wavelength portable scanning lidar system to derive information of particulate spatial aerosol distribution over remote distances. The lidar system and retrieval approach has been tested during several field campaigns measuring agricultural emissions from a swine feeding operation, almond orchard harvesting, and cotton gin processing. Test results show the great potential of lidar measurements to characterize particulate emission quantitatively and represent spatial and temporal variations of the emitted plume as 3-D/2-D mass concentration fields. To the best of the authors' knowledge, this is the first attempt to characterize the agricultural emission sources as density fields of the particulate classes $\left(\mathrm{PM}_{10}, \mathrm{PM}_{2.5}, \mathrm{PM}_{10}-\mathrm{PM}_{2.5}\right.$, and $\left.\mathrm{PM}_{1}\right)$ applicable to US EPA regulation practices.

Aglite uses an integrated approach to retrieve particulate mass concentration, fusing together in situ and remote measured data. The retrieval of optical parameters from a threewavelength lidar, coupled with a minimum least-squares solution, was found to be a valid method for retrievals of mass concentration in aerosol plumes. In situ measured data are used as boundary conditions for lidar retrievals, to determine the parameters of the lidar equation, and to establish a calibration factor, the MCF, for converting lidar data to mass concentration. The aerosol components during field experiments included background aerosols, emissions from agricultural facilities, and fugitive dust from unpaved roads. The strength of lidar returns from these sources varied by an order of magnitude, and the demonstrated retrieval algorithm gives meaningful results for all sources of particulate emissions.

Calibration and validation data are derived from TSP, $\mathrm{PM}_{10}, \mathrm{PM}_{2.5}$, and $\mathrm{PM}_{1}$ samplers and OPC sensors. A simple calibration procedure has been developed to convert the particle size distribution as measured by the OPCs to mass concentration units. Collocated FPS measurements and run time averaged OPC data from several locations are used to calculate an MCF for particles in the background and emitted plume. This MCF is then used to convert the OPC and lidar data to different fractions of mass concentration. The values of particulate emission mass concentration measured by the lidar agree with measurements by point sensor instruments within the stated error for all three experiment sights.

The main uncertainties involved in the retrieval process are due to errors in the cumulative volume concentration values retrieved from lidar data and in the MCF estimated from point sensor data. The lidar system typically operates at $20 \%$ of laser transmitted power to keep operations in the eye safety regime. In this case, the average errors in cumulative volume concentration for the typical deployment range of $600-1000 \mathrm{~m}$ are estimated at $10-15 \%$. Errors in MCF strongly depend on the homogeneity of experimental conditions and the influence of FPS data by background and additional sources of particulate matter that often occur during long sampling times required for filter-based sampling. Experimental MCF errors vary by $10-$ $20 \%$, leading to $10-32 \%$ total errors in lidar PM concentration retrievals in the eye safety regime.

Systematic error analyses presented in this study show that there are several ways to minimize the uncertainty in lidar retrievals. Real time PM sampling instruments employed on the downwind side of the facility will help to avoid the contamination typical for filter-based 
samplers. The experimental errors in MCF calculations are expected to be reduced to the level of $\sim 5-12 \%$, comparable with the accuracy of real time sampling instruments. The errors in cumulative volume concentration retrievals can also be reduced by applying more sophisticated digital filtering approaches to the data and new techniques for lidar retrievals. These advanced approaches can help reduce total measurement uncertainties in PM concentration retrieval to the level of $15-20 \%$. Future experiments are planned to test new retrieval and measurement approaches to verify the outlined improvements.

\section{Acknowledgements}

The development of the Aglite system was performed under USDA Cooperative Agreement number 58-3625-4-121. The authors gratefully acknowledge cooperation from Swine Graphics and R. Schwartz for the use of their swine production site and from the California Air Resources Board for facilitating the almond orchard and cotton gin experiments.

\section{References}

[1] G. E. Bingham, C. C. Marchant, V. V. Zavyalov, D. J. Ahlstrom, K. D. Moore, D. S. Jones, T. D. Wilkerson, L. E. Hipps, R. S. Martin, J. L. Hatfield, J. H. Prueger, and R. L. Pfeiffer, "Lidar based emissions measurement at the whole facility scale: method and error analysis," J. Appl. Remote Sens. 3(1), 033510 (2009) [doi:10.1117/1.3097919].

[2] B. A. Holmen, W.E. Eichinger, and R.G. Flocchini, "Application of elastic lidar to $\mathrm{PM}_{10}$ emissions from agricultural nonpoint sources," Envir. Sci. Technol. 32, 3066-3076 (1988).

[3] T. E. Stoughton and D. R. Miller, "Vertical dispersion in the nocturnal, stable surface layer above a forest canopy," Atmos. Env. 36(24), 3989-3997 (2002) [doi:10.1016/S1352-2310(02)00165-6].

[4] C. F. Bohren and D. R. Huffman, Absorption and Scattering of Light by Small Particles, Wiley, New York (1983).

[5] K. Rajeev and K. Parameswaran, "Iterative method for the inversion of multiwavelength lidar signals to determine aerosol size distribution," Appl. Opt. 37(21), 4690-4700 (1999) [doi:10.1364/AO.37.004690].

[6] D. Muller, U. Wandinger, and A. Ansmann, "Microphysical particle parameters from extinction and backscatter lidar data by inversion with regularization: theory," Appl. Opt. 38(12), 2346-2357 (1999) [doi:10.1364/AO.38.002346].

[7] C. Böckmann, "Hybrid regularization method for the ill-posed inversion of multiwavelength lidar data in the retrieval of aerosol size distributions," Appl. Opt. 40(9), 1329-1342 (2001) [doi:10.1364/AO.40.001329].

[8] C. Böckmann, I. Mironova, D. Muller, L. Schneidenbach, and R. Nessler, "Microphysical aerosol parameters from multiwavelength lidar," J. Opt. Soc. Am. 22(3), 518-528 (2005) [doi:10.1364/JOSAA.22.000518].

[9] I. Veselovskii, A. Kolgotin, V. Griaznov, D. Muller, U. Wandinger, and D. N. Whiteman, "Inversion with regularization for the retrieval of tropospheric aerosol parameters from multiwavelength lidar sounding," Appl. Opt. 41(18), 3685-3699 (2002) [doi:10.1364/AO.41.003685].

[10] I. Veselovskii, A. Kolgotin, V. Griaznov, D. Muller, K. Franke, and D. N. Whiteman, "Inversion of multiwavelength Raman lidar data for retrieval of bimodal aerosol size distribution," Appl. Opt. 43(5), 1180-1195 (2004) [doi:10.1364/AO.43.001180].

[11]V. A. Kovalev and W. E. Eichinger, Elastic Lidar-Theory, Practice and Analysis Methods, John Wiley \& Sons Inc, New Jersey (2004) [doi:10.1002/0471643173].

[12] O. Dubovik, B. Holben, T. F. Eck, A. Smirnov, Y. J. Kaufman, M. D. King, D. Kino, D. Tanre, and I. Slutsker, "Variability of absorption and optical properties of key aerosol 
types observed in worldwide locations," J. Atm. Sci. 59(3), 590-608 (2002) [doi:10.1175/1520-0469(2002)059<0590:VOAAOP $>2.0 . \mathrm{CO} ; 2]$.

[13] Y. Sasano and E. V. Browell, "Light scattering characteristics of various aerosol types derived from multiple wavelength lidar observations," Appl. Opt. 28, 1670-1679 (1989).

[14] M. Del Guasta, M. Morandi, L. Stefanutti, B. Stein, and J. P. Wolf, "Derivation of Mount Pinatubo stratospheric aerosol mean size distribution by means of a multiwavelength lidar," Appl. Opt. 33, 5690-5697 (1994).

[15] C. C. Marchant, T. D. Wilkerson, G. E. Bingham, V. V. Zavyalov, J. M. Andersen, C. B. Wright, S. S. Cornelsen, R. S. Martin, P. J. Silva, and J. L. Hatfield, "Aglite lidar: A portable elastic lidar system for investigating aerosol and wind motions at or around agricultural production facilities," J. Appl. Remote Sens. 3(1), 033511 (2009) [doi:10.1117/1.3097928].

[16] J. Binnig, J. Meyer, and G. Kasper, "Calibration of an optical particle counter to provide $\mathrm{PM}_{2.5}$ mass for well-defined particle material," J. Aerosol Sci. 38(3), 325-332 (2007) [doi:10.1016/j.jaerosci.2006.12.001].

[17] R. S. Martin, K. D. Moore, and V. S. Doshi, "Determination of particle $\left(\mathrm{PM}_{10}\right.$ and $\left.\mathrm{PM}_{2.5}\right)$ and gas-phase ammonia $\left(\mathrm{NH}_{3}\right)$ emissions from a deep-pit swine operation using arrayed field measurements and inverse Gaussian plume modeling," Proc. Ag. Air Quality: State of Science, 890-896 (2006).

[18] J. D. Klett, "Lidar inversion with variable backscatter/extinction ratio," Appl. Opt. 24, 1638-1683 (1985).

[19] A. S. Jursa, Handbook of Geophysics and the Space Environment, Air Force Geophysics Laboratory (1985).

[20] M. Hess, P. Koepke, and I. Schult, "Optical properties of aerosols and clouds: the software package OPAC," Bull. Am. Meteorol, Soc. 79(5), 831-844 (1998) [doi:10.1175/1520-0477(1998)079<0831:OPOAAC >2.0.CO;2].

[21] V. V. Zavyalov, G. E. Bingham, T. D. Wilkerson, J. Swasey, C. Marchant, C. Rogers, and T. Turpin, "Retrieval of physical properties of particulate emission from animal feeding operations using three wavelength elastic lidar measurements," Proc. SPIE: Optics and Photonics 6299, 62990S-1 (2006).

[22] J. R. Taylor, An Introduction to Error Analysis: The Study of Uncertainties in Physical Measurements, $2^{\text {nd }}$ ed., University Science Books, New York (1997).

[23] J. C. Chow, J. G. Watson, D. H. Lowenthal, L.-W A. Chen, R. J. Tropp, K. Park, and K. A. Magliano, " $\mathrm{PM}_{2.5}$ and $\mathrm{PM}_{10}$ mass measurements in California's San Joaquin Valley," Aerosol Sci. and Tech. 40(10), 796-810 (2006) [doi:10.1080/02786820600623711].

[24] W. C. Hinds, Aerosol Technology: Properties, Behavior, and Measurement of Airborne Particles, $2^{\text {nd }}$ ed., John Wiley \& Sons, New York (1999).

[25] J. W. Fitzgerald, "Effect of relative humidity on the aerosol backscattering coefficient at 0.694- and 10.6- $\mu \mathrm{m}$ wavelengths," Appl. Opt. 23, 4411-418 (1984). 